\title{
A SILICON MICROMACHINED GATE VALVE
}

\author{
M. Walters, V. Dhuler, R. Mahadevan, A. Cowen, R. Wood, E. Hill \\ $\mathrm{MCNC}$ \\ PO Box 12889 \\ Research Triangle Park, NC 27709
}

\author{
I. Kao \\ Dept. of Mechanical Engineering \\ State University of New York at Stoneybrook \\ Stony Brook, NY 11794
}

\begin{abstract}
A novel silicon based microvalve that incorporates a simple gate valve design is described. The design, fabrication, and operation of the valve are discussed. Experimental results are presented which show that silicon die of $4 \mathrm{mmx} 4 \mathrm{~mm}$ dimension that contain these valves are capable of controlling air flows in excess of $5000 \mathrm{sccm}$ with a momentary input power of less than 1 watt.
\end{abstract}

\section{INTRODUCTION}

Silicon microvalve technology has advanced over the past decade and is now competing with conventional solenoid valves in the commercial marketplace'. Current silicon microvalve technology incorporates multi-wafer stacks that utilize vertical displacement of a boss structure to open or close a valve orifice ${ }^{1}$. The maximum flow rate through these valves is limited by the amount of vertical displacement that can be obtained for a given actuation mechanism and bossed diaphragm size. For flow rates on the order of $1000 \mathrm{sccm}$, these valves typically employ bossed diaphragms approaching $1 \mathrm{~cm}$ in width, and can consume on the order of 1 watt of continuous power. ${ }^{1.2}$ This work presents an entirely new silicon microvalve based on a single wafer system comprised of a linearly actuated gate valve design. These gate valves can be designed to be normally open or normally closed, are capable of controlling higher gas flows while consuming less power, and are smaller and less expensive to manufacture than current silicon microvalves.

\section{DESIGN AND FABRICATION}

A cross-sectional representation of the gate valve design is shown in Fig. 1. Actuation of the valve gate is provided by MCNC's in-plane thermal actuator ${ }^{3}$, which has been shown to provide low voltage displacements up to $60 \mu \mathrm{m}$ and forces up to $15 \mathrm{mN}$. Fabrication of the valves was performed at MCNC. The sliding mechanism of the gate valve is comprised of electroplated nickel. Valve seats are formed from deposited polysilicon and nitride layers. Openings through the silicon substrate are fabricated using a combination of deep silicon reactive ion etching and $\mathrm{KOH}$ etching. Several designs were fabricated which incorporate a single actuator to close or open multiple openings for increased gas flow. Photographs of two of the fabricated designs are shown in Fig. 2 and 3. Supplying power to the actuator causes movement of the sliding gate mechanism. In the linear gate valve design (Fig. 2), the actuation distance supplies the full range of motion to completely traverse the $40 \mu \mathrm{m}$ wide openings, while in the rotary gate valve designs ( Fig. 3), mechanical advantage is used to provide motion over $200 \mu \mathrm{m}$ wide openings. An electrostatic clamping force is used to hold the valve gate in place once it has been switched, and springs are utilized to return the valve gate to its normal position when the electrostatic force is removed. Thus, appreciable power is only consumed during the short amount of time it takes to switch the valve from its normal state.

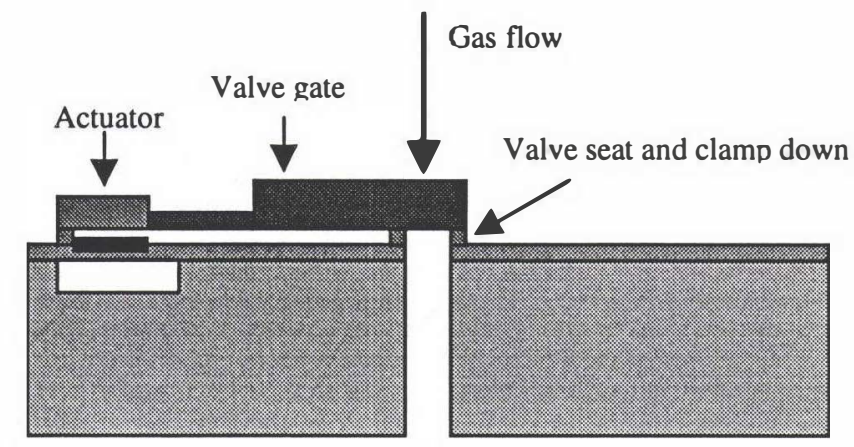

Figure 1: Schematic of a normally open gate valve design in the closed position. Power is supplied to the thermal actuator to move the valve gate. Once switched to the closed position, the power to the actuator is removed, and the valve gate is held in place using an electrostatic pull down voltage and the pressure from the gas flow. To switch back to the open position, the pull down voltage is removed and mechanical springs (not shown in schematic) are used to return the valve gate to its normal position

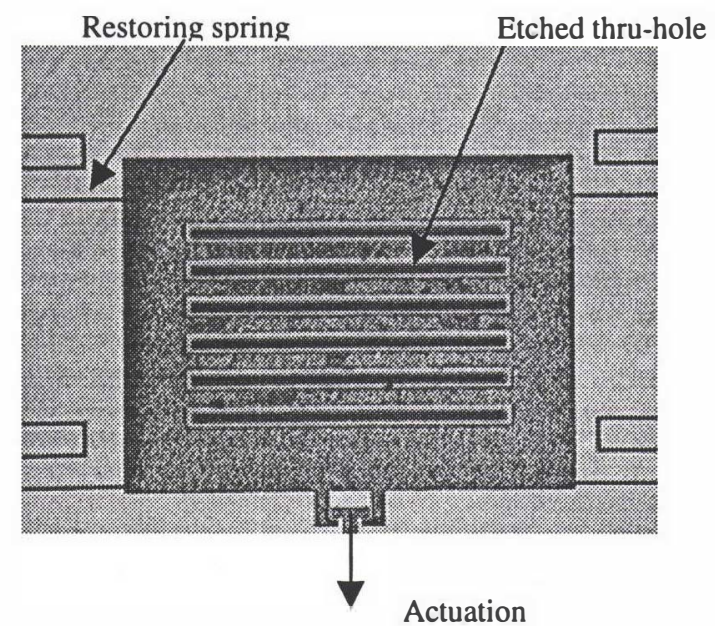

Figure 2: Fabricated normally open linear gate valve 


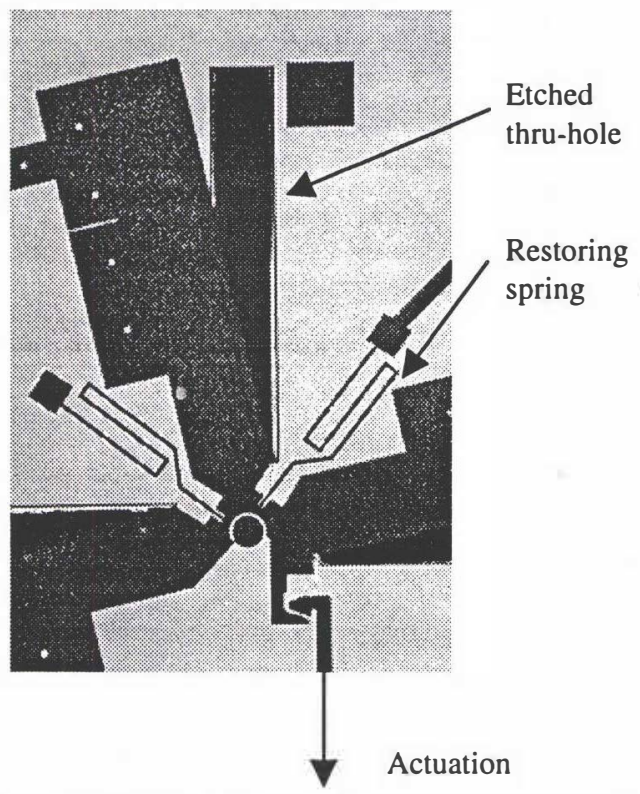

Figure 3: Fabricated normally open rotary gate valve

\section{EXPERIMENTAL RESULTS}

To facilitate flow testing, the valves were packaged in sealed T08 packages containing inlet and outlet ports available from T\&E industries of Orange, New Jersey. Testing of the valves was conducted at SUNY-Stoneybrook. The inlet port was connected to a pressure regulated compressed air supply. A pressure gauge at the inlet port was used to determine the supply pressure. A flowmeter with a range of 0 to $5000 \mathrm{sccm}$ was inserted at the outlet port. A power supply was used to provide the necessary current

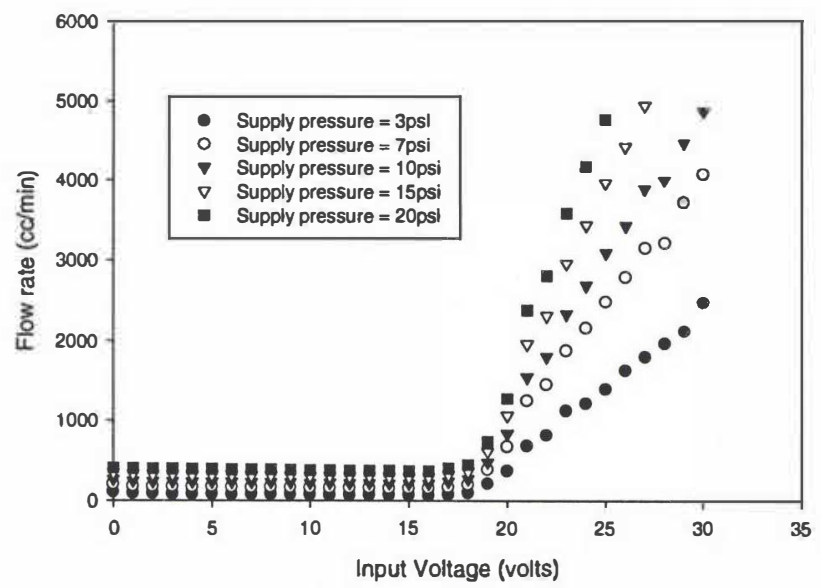

Figure 4: Measured flow rates as a function of input actuation voltage for a normally closed linear valve design (non-clamping).

and voltage for actuation and clamp down. Figure 4 shows a plot of the outlet flow rate versus applied voltage to the actuator for a normally closed linear valve design.
The data presented in Figure 4 is without a clamping voltage applied to the valve gate. The observed flow rates below $20 \mathrm{~V}$ of applied actuation voltage represent the leakage flow rates without clamping down the valve gate. When the valve gate was clamped down, these leakage rates were too low to be measured. Over the operating voltage range of $20-30$ volts, the input current was measured to be in the range of $27-30 \mathrm{~mA}$, yielding an input power level for valve actuation of $0.5 \mathrm{~W}$ to $1.1 \mathrm{~W}$.

The plot in figure 4 also shows that above an input actuation input of about $20 \mathrm{~V}$, the response of the valve is very linear, owing to the simple gate valve design. This linearity is further illustrated in figure 5, which shows a plot of the measured flow rates as a function if input pressure.

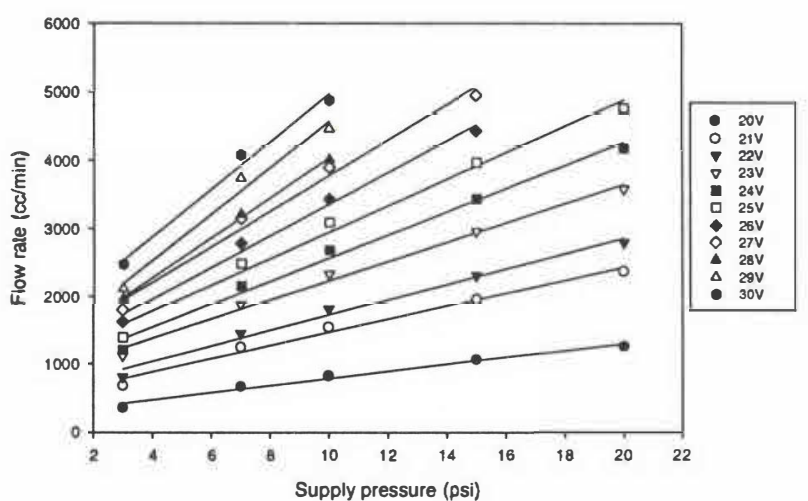

Figure 5: Measured flow rates as a function of supply pressure for a normally closed linear valve design).

\section{SUMMARY}

Table 1 summarizes the performance results obtained to date on the microvalve design presented in this paper. Because of their simple design and small size requirements, these valves are potentially more economical to manufacture than current commercially available diaphragm-based microvalves.

Table 1: Performance summary of the silicon micromachined gate valve

\begin{tabular}{|l|l|}
\hline Die size & $4 \mathrm{~mm} \times 4 \mathrm{~mm}$ \\
\hline Input Power & $\begin{array}{l}0.5-1.1 \text { Watt (to switch) } \\
<20 \mathrm{~mW} \text { (static) }\end{array}$ \\
\hline Response time & $\approx 50 \mathrm{msec}$ \\
\hline Max. Flow rate & $>5000 \mathrm{sccm}$ (at 10psi or higher) \\
\hline Max. Supply pressure & $>20 \mathrm{psi}$ \\
\hline
\end{tabular}

\section{REFERENCES}

[1] P.W. Barth, "Silicon Microvalves for Gas Flow Control", Technical Digest of the $8^{\text {h }}$ Int. Conf. On Solid-State Sensors and Actuators, and Eurosensors IX, Stockholm, Sweden, 6/2529,1995, pp 276-279.

[2] P.W. Barth, C.C. Beatty, L.A. Field, J.W. Baker, and G.B. Gordon, "A Robust Normally-Closed Silicon Microvalve", Technical Digest of the 1994 Solid-State Sensor and Actuator Workshop, Hilton Head Isl., SC, 6/13-16/94, Transducer Research Foundation, Cleveland (1994), pp. 248-250.

[3] MCNC Patent Pending 